\title{
Pants lining manufacturing survey of menswear brands in South Korea
}

\author{
Myoung-Ok Kim ${ }^{1 *}$ and Injoo Kim²
}

\author{
*Correspondence: \\ myokkim@howon.ac.kr \\ 1 Department of Fashion \\ Design, Howon University, \\ Gunsan-si, Jeollabuk-do \\ 54058 , Republic of Korea \\ Full list of author information \\ is available at the end of the \\ article
}

\begin{abstract}
This study aims to survey the pants lining manufacturing of menswear brands and to provide practical data for developing the pants lining pattern. The researchers collected data by interviewing patternmakers of thirteen menswear brands in Korea. The results of this study are as follows: first, $69.2 \%$ of menswear brands provide the pants lining pattern to the garment factory. Important factors in the patternmaking methods for the lining were the pant styles and the outer shell fabric's degree of stretch. Second, for manufacturing comparisons according to the pant style, the seam allowance from the back crotch line to the waistline showed that suit pants had varied seam allowance throughout the pant, while casual pants had the same seam allowance throughout the pant. Also, results showed that menswear pants lining were manufactured only in the front for the suit pants lining. Third, ease in the pants lining pattern the waist, hip, and thigh were the same $0.75 \mathrm{~cm}$. Due to the specific shifting amount in ease, the lining pattern increases in size. The length of the back could be adjusted whether the length is below the crotch level or below the knee level. Therefore, this study suggests that when the pants lining is manufactured, the manufacturer should consider these results to develop the proper pants lining pattern, a task equally important as the outer shell pattern.
\end{abstract}

Keywords: Menswear, Suit pants, Casual pants, Lining pattern

\section{Introduction}

Increasing interest in men's fashion upon entering the 21st century has led to a steady growth in the menswear market. When it comes to garments for the lower part of the body, pants are the most common item for menswear compared to womenswear, which includes both skirts and pants (Kim and Kim 2014). For upper-body garments, there are many items, such as shirts, T-shirts, sweaters, vests, jackets, and coats. However, for the men's lower garments, pants are the most common. With the high fashion interest, menswear pants designs have become varied; from the typical suit pants (with no pleat, one pleat, and two pleats on the front) to casual pants (denim pants, cargo pants, baggy pants, and sports pants, etc.).

The term "lining" refers to any fabric used on the inside of a garment, and is different from the outer shell fabric (Knowles 2006). Even though the lining is placed inside of the garment, the size of the lining needs to be larger than the outer shell, so as not to cling to the outer shell nor disturb it. Appropriate ease in the lining pattern is necessary,

(c) $2015 \mathrm{Kim}$ and Kim. This article is distributed under the terms of the Creative Commons Attribution 4.0 International License (http://creativecommons.org/licenses/by/4.0/), which permits unrestricted use, distribution, and reproduction in any medium, provided you give appropriate credit to the original author(s) and the source, provide a link to the Creative Commons license, and indicate if changes were made. 
otherwise the lining will pull or disrupt the outer shell fabric. Therefore, developing a lining pattern is as important as the patternmaking of the outer shell fabric.

There have been recent studies on menswear, due to the increased in interest in this category. Examples of this research include development of the slim-fit jacket (Cho 2008; Yang and Seong 2011), an establishment of crotch ease of men's slacks (Kim 2008), and 3D body scanner testing (Suh and Chun 2004; Hong and Suh 2012). In addition, there have been studies regarding the lining as an apparel material sector (Kim et al. 2006) and about lining manufacturing for men's jackets (Kim 2014).

While many studies have been focusing on menswear jacket developments, there has been little attention given specifically to pants lining manufacturing and to lining patternmaking. Along with the jacket, pants manufacturing is important, because this garment is the lower part of the suit, an important business wear item. Therefore, this study aimed to research the pants lining manufacturing of menswear brands and to provide practical data for manufacturing and developing the lining pattern of pants. The data was accumulated by analysis of surveyed general lining manufacturing situations, as well as compared and contrasted elements of suit pants and casual pants manufacturing through a survey of menswear manufacturing brands.

\section{Literature review}

\section{Functions and fabrics of linings}

A lining is an additional layer of fabric that is attached to the interior of a garment in order to conceal seams (Kim and Kim 2014). In addition to concealing such areas as the seams, threads, interlining, and pockets, the purpose of attaching the lining is for the ease and comfort of the wearer. It is especially necessary for the pants to have the lining in the front upper area, to improve the fit, and cover the front pocket and front zipper.

In addition, the function of the lining is for this element to reflect the silhouette of the outer shell, so that the garment is smooth when wearing, to minimize friction when wearing, and for easy removal of the garment from the wearer's body (Kang and Suh 2007). The fabric of the lining depends on the outer shell fabric and its color. In general, the guiding point is to choose the similar color to the outer shell and a solid plain lining color. Use of a synthetic lining fabric is standard for low to mid priced garment manufacturing, while silk is used for higher priced garments. The most popular lining fiber types are polyester, rayon, and acetate. The structure of the fabric is dependent upon the season in which the garment is intended to be worn. Plain weave is for spring and summer garments, while plain weave and twill are suitable for fall garments, and twill and satin are for winter-wear garments (Kim and Suh 2007).

Lining fabrics are typically made in a lighter weight and smoother texture than the outer shell fabric. Generally, the lining fabrics do not stretch, but occasionally, a stretchable garment will be lined with a stretch lining fabric (Knowles 2006). If the degree of stretch in the lining fabric is less than the outer shell fabric, the lining pattern size is increased from the outer shell pattern (Kim and Suh 2007). The amount of increase in overall size for non-stretch fabric lining patterns from the non-stretch outer shell patterns results in a pattern piece larger than the non-stretch outer shell fabric. The nonstretch outer shell pattern size is larger than the stretch outer shell fabric pattern size to accommodate for more ease in the garment. 


\section{Methods of pants lining patternmaking}

Depending on the area of the garment, the lining should be larger and longer than the outer shell, so that the lining has sufficient ease. If there is not sufficient ease, the constant pulling and friction that the lining is subject to, will cause tears in the lining fabric (Cabrera 1996). Previous research showed that the jacket lining is $2.4-5.6 \mathrm{~cm}$ larger than the outer shell pattern in the chest circumference (Kim 2014). Along with the consideration of circumference ease when developing a pants lining pattern, length ease from the waist to the hem is also important when over-locking is performed in the sewing process. This is due to the general placement of the lining in the front area of the pant only. Thus, the circumference ease and length ease of the pant lining would be different from the jacket lining ease.

There has been little research and reference regarding pants lining patternmaking methods. The suggested manufacturing methods for pants lining in literature (Nam and Lee 2005; Kwak et al. 2008) are as follows: $1 \mathrm{~cm}$ circumference ease on the front and $0.5 \mathrm{~cm}$ from the both the inseam line and the outseam line. As the circumference increases, the front crotch length increases. The length for the pants lining may be 7-10 $\mathrm{cm}$ below the knee line of the pant leg.

As discussed above, the pants lining patternmaking method was not varied, because the literature regarding the pants lining patternmaking was rare. However, this lack of literature and attention does not mean the pant lining pattern manufacturing is not important. Systematic research and analysis is needed for the manufacturing of men's pants lining through surveys on the pants lining patterns in menswear brands.

\section{Methods}

\section{Data collection}

In this study, the researchers collected data using prepared questionnaires to interview patternmakers of thirteen Korean menswear brands, which were registered on the Korean fashion brand annual 2012/2013. Also, the brands' yearly sales in 2010-2011 were considered, which brought in over 8,000,000,000 Korea won (Table 1). A preliminary survey for this research was conducted from November 4th through 15th, 2013, with two companies using on-site interviewing and telephone interviewing. The main on-site interviewing was conducted about $1 \mathrm{~h}$ from December 23, 2013 through February $28,2014$.

The interview questionnaires were based on previous research conducted by Kim and Suh (2007), Lee and Suh (2008), and it was modified after the preliminary survey was

Table 1 General information of the responding companies

\begin{tabular}{llllll}
\hline Company Name & Brand Name & Target Age & Company Name & Brand Name & Target Age \\
\hline Cheil Industries & Pal Zileri & $29-59$ & Shinwon & Sieg & $25-35$ \\
& Galaxy & $30-50$ & Solid Homme & Solid Homme & $25-35$ \\
Gnco & T.l. for Men & $25-32$ & The Basic House & The Class & $20-35$ \\
Handsome & Time Homme & $25-35$ & & Durban & 20 's-30's \\
& System Homme & 30 's & Tomboy & Comodo Square & $24-39$ \\
Hyungji & Arnaldo Bassini & $30-50$ & Zishen & Zishen Homme & 40 \\
LG Fashion & Daks & Late 30's to 50's & & & \\
\hline
\end{tabular}


completed. The questionnaires were comprised of general questions regarding pants lining manufacturing, comparisons and contrasts between suit pants and casual pants, and the specific shifting distance to create the lining patterns.

For development of the lining pattern, a single pleat style pant was used for the design of the outer shell pattern (Figures 1,2). As in the figures below, the pants on the front have a single pleat and a front angled pocket; on the back, two darts and a welt pocket.

\section{Data analysis}

The data analysis for this study used SPSSWIN Ver.18.0 for the descriptive statistics (frequency and average). The descriptive statistics were used for comparisons of pants lining manufacturing between suit pants and casual pants, ease of the pants lining patterns from the outer shell patterns, and specific shifting methods.

\section{Results and discussion}

\section{General information of pants lining manufacturing}

The results of the general information regarding the pants lining manufacturing are shown in Table 2.

In general, most menswear brands provide the pants lining pattern to the subcontractor $(69.2 \%$, 9 out of 13 surveyed). This result was in contrast to that of Korean womenswear companies, where only $20 \%$ of such companies provided the pants lining pattern to the subcontractor (Lee and Suh 2008). It was most crucial to determine if the lining manufacturing methods of pants were for suit pants or casual pants (53.8\%, 7 out of 13), rather than determining the degree of the outer shell fabric's stretch capability (38.5\%, 5 out of 13). The most important part to developing the pants lining pattern was "all circumference and length" (53.8\%, 7 out of 13 ) and "length ease" (30.8\%, 4 out of 13$)$.

The construction method that connected a lining fabric to the outer shell fabric was separate over-locking sewing steps (the front lining was overlocked to front outer shell, the back was overlocked to the back outer shell), then all were sewn together $(84.6 \%$, 11 out of 13). The important factors on the length of the lining pattern were "the
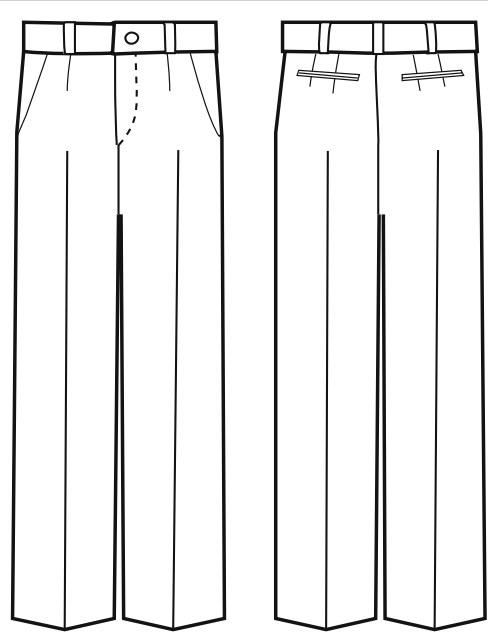

Figure 1 Experimental pants design. 

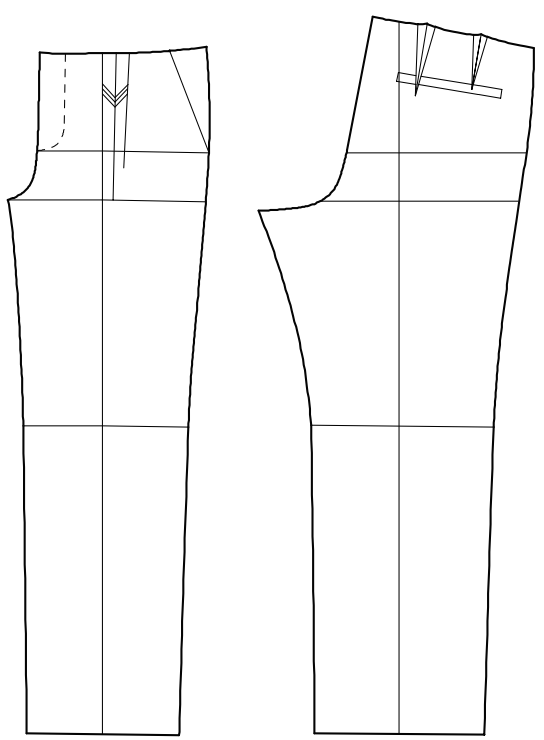

Figure 2 Experimental pants outer shell pattern without seam allowance.

\section{Table 2 Pants lining patternmaking manufacturing condition of the companies}

\begin{tabular}{|c|c|c|}
\hline Items & Statements & $\mathrm{N}(\%)$ \\
\hline \multirow[t]{4}{*}{ Providing lining patterns to factory } & Always provide & $9(69.2)$ \\
\hline & Do not provide & $1(7.7)$ \\
\hline & Others & $3(23.1)$ \\
\hline & Total & $13(100.0)$ \\
\hline \multirow{4}{*}{$\begin{array}{l}\text { Crucial factors on the lining patternmaking } \\
\text { methods of pants }\end{array}$} & Style (suit pants or casual pants) & $7(53.8)$ \\
\hline & $\begin{array}{l}\text { Fabric of pants outer shell (stretchable or } \\
\text { non-stretchable) }\end{array}$ & $5(38.5)$ \\
\hline & $\begin{array}{l}\text { Fabric of pants lining (stretchable or } \\
\text { non-stretchable) }\end{array}$ & $1(7.7)$ \\
\hline & Total & $13(100.0)$ \\
\hline \multirow{5}{*}{$\begin{array}{l}\text { Most important areas to develop pants lining } \\
\text { pattern }\end{array}$} & All circumference and length & $7(53.8)$ \\
\hline & Length ease & $4(30.8)$ \\
\hline & Hip area & $1(7.7)$ \\
\hline & Front knee area & $1(7.7)$ \\
\hline & Total & $13(100.0)$ \\
\hline \multirow[t]{4}{*}{$\begin{array}{l}\text { Pants lining sewing method (when both front } \\
\text { and back are sewn together) }\end{array}$} & $\begin{array}{l}\text { After sewing the outer shell and lining separately, } \\
\text { sew together at the waist }\end{array}$ & $1(7.7)$ \\
\hline & $\begin{array}{l}\text { After putting lining onto outer shell using over } \\
\text { locking stitch, sew together. }\end{array}$ & $11(84.6)$ \\
\hline & No response & $1(7.7)$ \\
\hline & Total & $13(100.0)$ \\
\hline \multirow[t]{4}{*}{ Important factors on the length of lining pattern } & Comfortableness on the knee area & $7(53.8)$ \\
\hline & Product cost by fabric consumption & $4(30.8)$ \\
\hline & Others & $2(15.4)$ \\
\hline & Total & $13(100.0)$ \\
\hline \multirow[t]{3}{*}{ Direction of grain line } & Crosswise & $12(92.3)$ \\
\hline & Lengthwise & $1(7.7)$ \\
\hline & Total & $13(100.0)$ \\
\hline
\end{tabular}


comfortableness on the knee area" (53.8\%, 7 out of 13) and "product cost by fabric consumption" (30.8\%, 4 out of 13$)$.

The direction of pant lining fabric used was a cross grain (92.3\%, 12 out of 13). This is because it has several benefits. The cross grain direction has less shrinkage than a lengthwise direction. In addition, the selvage of lining fabric can be used for hemming of the pants lining without an additional overlocking process, saving both time and fabric consumption. Interesting results were obtained in contrast to that of the women's pants and other garments, which used the selvage direction as vertical use of grain in a traditional manner.

As illustrated above, most menswear brands provided the pants lining pattern to the garment factories. The pants style (suit pants and casual pants), as well as both circumference and length ease were important factors. The connecting method was overlocking the lining fabric onto the outer shell fabric. The direction of the lining fabric used was crosswise grain line, which is in contrast to the information for the womenswear manufacturers and designers. Therefore, the results of this study could be a great asset for new menswear and womenswear manufacturers and fashion designers.

\section{Manufacturing condition according to pant styles}

The results of the manufacturing condition according to pants styles are shown on the Table 3.

For pants manufacturing according to the pants style (suit pants, casual pants), most menswear brands used the pattern with included seam allowances regardless of pants styles (suit pants, $84.6 \%$; casual pants, $61.5 \%$ ). Ease on the lining patterns from the outer shell patterns (according to the typical pants designs such as no-pleat, one-pleat, twopleats pants) were the same regardless of the pants style (suit pants, 92.3\%; casual pants, $84.6 \%$ ).

Table 3 Manufacturing condition according to pant styles (suit pants vs. casual pants)

\begin{tabular}{|c|c|c|c|}
\hline Items & Statements & Suit pants N (\%) & Casual pants N (\%) \\
\hline \multirow[t]{4}{*}{ Pants pattern shape } & All seam allowances & $11(84.6)$ & $8(61.5)$ \\
\hline & No seam allowances & $2(15.4)$ & $4(30.8)$ \\
\hline & Partial-seam allowances & $0(0.0)$ & $1(7.7)$ \\
\hline & Total & $13(100.0)$ & $13(100.0)$ \\
\hline \multirow{3}{*}{$\begin{array}{l}\text { Ease of pants lining patterns according } \\
\text { to no-pleat, one-pleat, and two-pleat } \\
\text { designs }\end{array}$} & Same & $12(92.3)$ & $11(84.6)$ \\
\hline & Not the same & $1(7.7)$ & $2(15.4)$ \\
\hline & Total & $13(100.0)$ & $13(100.0)$ \\
\hline \multirow{3}{*}{$\begin{array}{l}\text { Crotch seam allowances from hip area } \\
\text { to waistline on the back pattern } \\
\text { pieces }\end{array}$} & Constant & $0(0.0)$ & $7(53.8)$ \\
\hline & Gradually widened & $13(100.0)$ & $6(46.2)$ \\
\hline & Total & $13(100.0)$ & $13(100.0)$ \\
\hline \multirow{3}{*}{$\begin{array}{l}\text { Waistband seam shape on the center } \\
\text { back line }\end{array}$} & Folded line on the center back & $0(0.0)$ & $7(53.8)$ \\
\hline & Seam on the center back & $13(100.0)$ & $6(46.2)$ \\
\hline & Total & $13(100.0)$ & $13(100.0)$ \\
\hline \multirow{5}{*}{$\begin{array}{l}\text { Lining parts that were manufactured } \\
\text { for pants }\end{array}$} & Front only & $13(100.0)$ & $5(38.5)$ \\
\hline & Front + Back & $0(0.0)$ & $1(7.7)$ \\
\hline & Others & $0(0.0)$ & $4(30.8)$ \\
\hline & No respond & $0(0.0)$ & $3(23.1)$ \\
\hline & Total & $13(100.0)$ & $13(100.0)$ \\
\hline
\end{tabular}


This was the result of there not being any increase in ease on the circumference area for the pants. Most menswear brands developed the pants lining patterns by increasing the circumference about $0.5 \mathrm{~cm}$ at each end of pattern. There were several brands, however, which reduced the pant's overall ease when the pants design had pleats, because pleat design had the ease built into it already. These brands reduced the pleat amount or converted the two pleats into one pleat when developing the lining pattern.

There were interesting differences between the suit pants and the casual pants in seam allowances from the back crotch curve to the waistline. The suit pants pattern had different seam allowances throughout the garment (100\%, 13 out of 13), while the casual pants pattern used the same amount throughout (53.8\%, 7 out of 13). There could be several reasons for the differences: the price of suit pants is higher than the casual pants, so consumers would want to wear the suit pants for a longer period of time. In this case, individual alterations to the pants can take place as needed, since one's body shape, especially the waist circumference, changes with age. The seam allowance for suit pants near the hip line, $1-1.3 \mathrm{~cm}$, was increased to $2.5-3.0 \mathrm{~cm}$ on the waistline to prepare for the individual alteration. In contrast, the casual pants used the same 1-1.3 cm seam allowances on all areas of the garment, because alterations are not as common for casual pants. Consequently, the waistband shape on the center back line was different between the two pant types. The suit pants potentially need to be altered, while casual pants do not. The suit pants had a seam on the center back of the waistband and the casual pants had seamless center back line.

The front-only lining patterns that were manufactured for suit pants were for $100 \%$ of the companies participating (13 out of 13), while the casual pants response for frontonly lining patterns was $38.5 \%$ ( 5 brands out of 13 ). The reason that the front-only lining was used for menswear pants, was that if the back lining existed, it would disturb the movement of the wearer. The fit of the pant would not be as comfortable as possible and could cause the lining to become twisted. Thus, it is the general case that all suit pants do not have a back lining piece. There are some exceptions to this guideline, however. If the outer shell fabric of the pant is too rough or too sheer, then a back lining piece is used to for comfort and modesty.

As discussed above, there were similar factors: the casual menswear brands used the patterns that included seam allowances and the same amount of ease on the lining patterns from the outer shell patterns. The structures of these patterns were the same for the typical pants designs regardless of pants style. There were differences in seam allowances on the back crotch line and the waistband seam in suit pants. In addition, using only the front lining piece for the suit pants was most common and expected. The casual pants occasionally used a back lining piece since the designs and fabrics vary for this pant style. These results could provide great reference data for future menswear designers or manufacturers, so as to save time and cost when manufacturing the pants lining according to pant styles.

\section{Pants lining pattern development in menswear brands} Ease on the pants lining pattern

From the preliminary interviewing, the researchers found that there was not a significant difference between suit pants and casual pants in regards to the amount of ease in 
the patterns. That resulted in the ease of the pants lining being effective for both suit pants and casual pants (Table 4).

Average ease on the waist, hip, and thigh circumference was $0.75 \mathrm{~cm}$. Minimum ease was $0 \mathrm{~cm}$ and maximum ease was $1 \mathrm{~cm}$ in those areas. When comparing literature, this ease study showed a smaller amount of ease than that in other studies (Nam and Lee 2005; Kwak et al. 2008), which documented $1 \mathrm{~cm}$. The average front crotch ease was $0.43 \mathrm{~cm}$. This minimum ease was also $0 \mathrm{~cm}$ and the maximum ease was $1 \mathrm{~cm}$. This front crotch ease was similar to the comparative literature data of $0.5 \mathrm{~cm}$. The average back crotch ease was $0.52 \mathrm{~cm}$. This minimum ease was also $0 \mathrm{~cm}$, while the maximum ease was $1.1 \mathrm{~cm}$. The back crotch ease was used only if there is a back lining, as in some casual pants. The back crotch ease was $0.52 \mathrm{~cm}$. This minimum ease was also $0 \mathrm{~cm}$ while the maximum ease was $1.1 \mathrm{~cm}$. The length ease of $0.07 \mathrm{~cm}$ on the lining gave room when overlocking the lining fabric to outer shell fabric. The average knee ease was $0.61 \mathrm{~cm}$. The information documented from this study was new, since there was no written guide or reference for this lengthwise ease of the pants lining.

As discussed above, the ease in the pants lining pattern was slightly different from reference material and there was additional lengthwise ease, which was not mentioned in the references. These results should be shared with all manufacturing companies, as it is vital information for future fashion designers.

\section{Degree of movement from the outer shell pattern to develop the lining pattern}

To learn a specific pattern development for pants lining, the researchers surveyed the specific shift amount of the pants lining pattern. The results are shown in Table 5, referring to locations in Figure 3.

Due to the ease in the pants lining, the specific moving degrees on the pattern to develop the lining pattern from the outer shell pattern was different. As shown in Table 3, the suit pants lining was for the front only, and the back patterns in Figure 3 are for casual pants. The back pants lining showed two different types. One type of lining has the length below the knee line (average $2.3 \mathrm{~cm}$ below the knee level), which is a match up with the front lining panel. The second type has the length below the crotch level (average $7.2 \mathrm{~cm}$ below the crotch level), and is shorter than the front lining panel. This shortened back lining panel reduces the potential discomfort of the wearer.

On the front, the $X$ values of the point (1), (2), and (3) were the same as $-0.34 \mathrm{~cm}$, which means moving to left from the center front line. The counterpart point (5), (6) $\mathrm{X}$ values

Table 4 Ease on the Pants Lining Patterns $(\mathrm{N}=13)$

\begin{tabular}{lllll}
\hline Areas & Min. & Max. & M & SD \\
\hline Waist ease & 0 & 1.0 & 0.75 & 0.31 \\
Hip ease & 0 & 1.0 & 0.75 & 0.31 \\
Thigh ease & 0 & 1.0 & 0.75 & 0.31 \\
Front crotch length ease & 0 & 1.0 & 0.43 & 0.37 \\
Back crotch length ease (in case of back lining) & 0 & 1.1 & 0.52 & 0.42 \\
Knee ease & 0 & 1.0 & 0.61 & 0.38 \\
Lengthwise ease & 0 & 2.0 & 0.7 & 0.596 \\
\hline
\end{tabular}


Table 5 Specific shifting degrees on pants lining patterns

\begin{tabular}{|c|c|c|c|c|c|c|c|c|c|c|c|}
\hline \multicolumn{2}{|c|}{ Each point } & \multicolumn{4}{|l|}{ Front } & \multicolumn{2}{|c|}{ Each point } & \multicolumn{4}{|l|}{ Back } \\
\hline & & Min. & Max. & $M$ & SD & & & Min. & Max. & $M$ & SD \\
\hline \multirow[t]{2}{*}{ (1) } & $x$ & -0.50 & 0 & -0.34 & 0.182 & (1) & $x$ & -0.50 & 0 & -0.40 & 0.177 \\
\hline & y & 0 & 1.00 & 0.42 & 0.373 & & $y$ & 0.00 & 1.00 & 0.41 & 0.385 \\
\hline (2) & $x$ & -0.50 & 0 & -0.34 & 0.182 & (2) & $x$ & -0.50 & 0 & -0.40 & 0.177 \\
\hline (3) & $x$ & -0.50 & 0 & -0.34 & 0.182 & (3) & $x$ & -0.50 & 1.00 & -0.22 & 0.491 \\
\hline (4) & $x$ & -0.50 & 0.30 & -0.18 & 0.299 & (4) & $x$ & -0.50 & -0.25 & -0.43 & 0.125 \\
\hline \multirow[t]{2}{*}{ (5) } & $x$ & 0 & 0.60 & 0.40 & 0.163 & (5) & $x$ & 0.25 & 0.50 & 0.45 & 0.100 \\
\hline & y & 0 & 1.00 & 0.42 & 0.373 & & y & 0.00 & 1.00 & 0.41 & 0.385 \\
\hline (6) & $x$ & 0 & 0.60 & 0.40 & 0.163 & (6) & $x$ & 0.25 & 0.50 & 0.450 & 0.100 \\
\hline (7) & $x$ & 0 & 0.60 & 0.35 & 0.208 & (7) & $x$ & 0.25 & 0.50 & 0.43 & 0.125 \\
\hline \multirow[t]{2}{*}{ (8) } & y & -7.00 & 5.00 & -2.30 & 3.276 & (8) & y & -7.00 & 5.00 & -2.30 & 3.276 \\
\hline & & - & - & - & - & (8) & y & -10.00 & -1.00 & -7.22 & 3.701 \\
\hline
\end{tabular}

$x, y$ coordinates value means the shifting distance from each point.

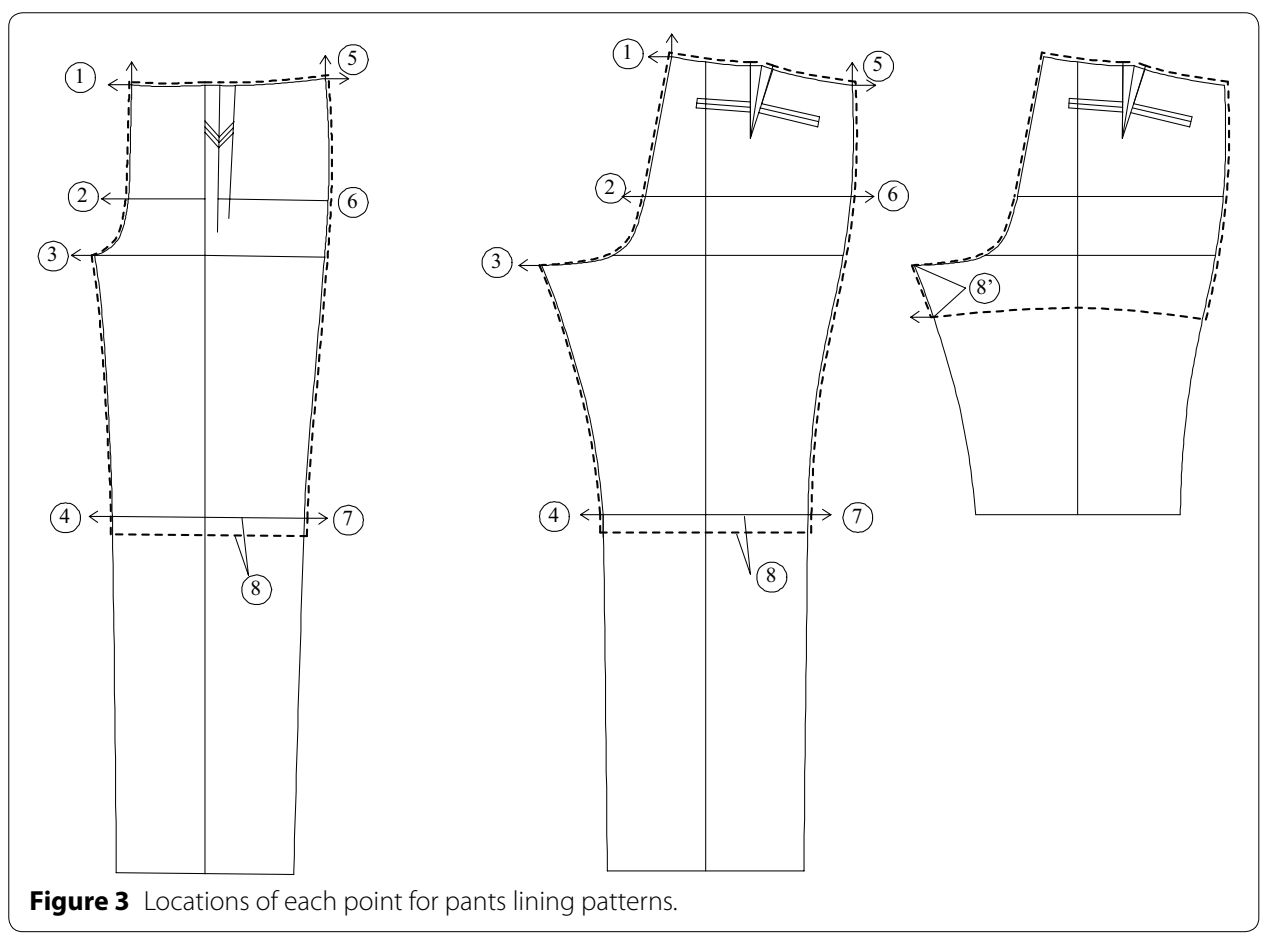

were the same as $0.4 \mathrm{~cm}$, which means moving to the right from the side seam. The bottom of the lining pattern (around the knee level), the point (4) and (7) values are -0.18 and $0.35 \mathrm{~cm}$. These values are not similar; the inseam point (4) $(-0.18 \mathrm{~cm})$, was less than the outseam point $(7)(0.35 \mathrm{~cm})$. The point (8), which determines the length of the pants lining was $-2.31 \mathrm{~cm}$ below the knee line. The length of pants lining varied; the longest lining panel was $7 \mathrm{~cm}$ below the knee line, while the shortest one was $5 \mathrm{~cm}$ above the knee line. These results were also different from the comparative literature, which stated $10 \mathrm{~cm}$ below and $7 \mathrm{~cm}$ below the knee line was average. The length of the pants lining pattern in menswear brands was shorter than that in the literature reviews. 
On the back lining pattern for casual pants, $X$ values of point (1) and (2) were the same $-0.4 \mathrm{~cm}$, which means moving to left from the center back line. The counterpart point (5), (6) $\mathrm{X}$ values were the same as $0.45 \mathrm{~cm}$, which means moving to the right from the side seam. Point (3) was $-0.22 \mathrm{~cm}$. The maximum $\mathrm{X}$ value was $1 \mathrm{~cm}$ which, when moving to the right side, means reducing the width. The values of point (4) and (7) were the same distance each -0.43 and $0.43 \mathrm{~cm}$. In case of a short back lining, point 88 was $-7.2 \mathrm{~cm}$, which means $7.2 \mathrm{~cm}$ below the starting point of the inseam line.

Results of this survey showed that the pants lining patterns were not the same as the outer shell pattern size. In addition, specific shifting degrees on the pants lining patterns were not simple, whether it is the suit pants or casual pants. Especially, for the casual pants, the length of back lining fit into two categories either knee length or crotch length. Manufacturers of men's pants should consider these specific results to save time and cost when manufacturing both styles of pants.

\section{Treatment of pleats and darts}

The researchers also surveyed the treatment of pleats and darts, because when sewing the pants lining, the darts could be turned into tucks as a simplified mode of construction. Also, as the lining fabric has weaker strength than the outer shell fabric, tucking is reasonable. This construction process was different depending on the manufacturer's discretion. Results of how to treat pleats and darts are shown in Table 6.

On the front pattern, as expected, all menswear brands kept the pleats when they developed the lining pattern of the one-pleat pants or the two-pleat pants designs. However, there was a slight change on the back pattern; $61.5 \%$ of brands (8 out of 13) kept the dart, while $38.5 \%$ ( 5 out of 13 ) converted the dart into one tuck. This change in construction increased when there were two darts on the back of the pant. $46.2 \%$ of brands ( 6 out of 13) kept the two darts on the back of the pant, 15.4\% ( 2 out of 13) of brands merged the two darts into one dart, $7.7 \%$ (1 out of 13) converted the darts into one tuck, and $30.8 \%$ ( 3 out of 13 ) of brands converted the darts into two tucks.

In addition, the researchers analyzed the process of how to combine the lining and outer shell fabrics, along with manufacturing the pocket and darts on the pants. There were two cases of construction methods found for these areas of the pants. In the first

Table 6 How to treat pleats and darts when developing the pants lining pattern

\begin{tabular}{llc}
\hline Items & Statements & N (\%) \\
\hline On front: one-pleat or two-pleat pants designs & Keep pleat & $13(100.0)$ \\
& Add pleat or dart & $0(0.0)$ \\
One dart on the back pattern & Total & $13(100)$ \\
& Keep one dart & $8(61.5)$ \\
Two darts on the back pattern & Convert into one pleat & $5(38.5)$ \\
& Total & $13(100.0)$ \\
& Keep two darts & $6(46.2)$ \\
& Convert into one dart & $2(15.4)$ \\
& Convert into one tuck & $1(7.7)$ \\
& Convert into two tucks & $4(30.8)$ \\
& Total & $13(100.0)$ \\
\hline
\end{tabular}


case, after stitching the lining to the outer shell by using an overlocking stitch, manufacturers sewed two layers (lining and outer shell) of the darts and pocket. This method of construction was not expected and was done for a lower manufacturing price. In the second case, the sewing of the darts and pocket of the outer shell and the lining were done separately, then the lining piece was attached to the outer shell at the waistline.

There were several manufacturing methods for details of pleats and darts. The front pleats were kept in the lining pattern, since pleats are easier to construct than sewing darts. Depending on the particular menswear brands, the darts were converted into tucks to save time and manufacturing cost, as well as to give ease on the waist area of the lining. Therefore, this analysis shows that an intelligent choice is necessary when manufacturing the back pants lining.

\section{Conclusions}

This study was designed to examine the general information of menswear pants lining manufacturing conditions, in order to discover the amount of ease of the pants lining pattern and to determine the specific shifting amount when the pants lining pattern was developed. The methodology of this study focused on interviewing thirteen menswear brands in South Korea. The results of this study are as follows:

First, in general, menswear brands provide the pants lining pattern to the factory. The pant style (suit or casual) and the outer shell fabric's degree of stretch were important factors with regards to the patternmaking method of the pants lining. The sewing method of pants lining has several steps. For example, attaching the lining fabric onto the outer shell fabric using an overlocking stitch must be done first. Then, the sewing of both layers together can be done to construct the remainder of the pant. Interestingly, it was noted that the direction of the grain line was crosswise instead of lengthwise for the lining fabric.

Second, the manufacturing comparisons and contrasts of two pant styles (suit pants and casual pants) showed that the amount of seam allowance from the back crotch line to the waistline in the suit pants varied to allow for the alteration of the waist circumference. The casual pants, however, had the same amount of seam allowance throughout the pant. Also, results showed that the menswear pants lining was manufactured only in the front for suit pants. Occasionally, the back pants lining was necessary for casual pants.

Third, ease in the pants lining pattern at the waist, hip, and thigh were the same measurement of $0.75 \mathrm{~cm}$. To ensure that the outer shell is comfortable when worn, the lining pattern had ease on the circumference and length, even though the back lining panel hangs freely within the pant shell. Due to the horizontal and vertical ease, a specific shifting amount was necessary to increase the size of the lining pattern. The length of the back lining panel could be adjusted to reach just below the crotch level or below the knee level.

In conclusion, the researchers found that the pants lining pattern size was increased in circumference and in length from the outer shell pattern size. The casual pants manufacturing was varied from that of the suit pants, as the casual pants occasionally have a back lining panel. This was in contrast to womenswear pants manufacturing. Therefore, this study suggests that new menswear manufacturers or womenswear fashion designers 
could apply these specific results when developing pants lining patterns. As the study results show, pants lining patterns are as important as the outer shell patterns. Garment manufacturers should take these results into consideration to develop proper menswear pants lining patterns. We believe that this study will contribute to an area of clothing construction science applying study results, and save construction time and manufacturing cost sharing companies' information. For future research, more detailed manufacturing conditions and methods of casual pants is suggested. More in-depth studies comparing and contrasting menswear with womenswear pants manufacturing is also suggested.

\section{Authors' contributions}

MOK developed the literature review and the ideological frame work, the research frame work, conducted interviews with pattern makers in thirteen menswear brands, and drafted the manuscript. IK guided the development of the interview questionnaire, the literature review and the ideological frame work, the research frame work, and the analysis of the interview results. Both authors read and approved the final manuscript.

\section{Author details}

${ }^{1}$ Department of Fashion Design, Howon University, Gunsan-si, Jeollabuk-do 54058, Republic of Korea. ${ }^{2}$ Fashion Design Program, University of Cincinnati, Cincinnati, USA.

Acknowledgements

This study was supported by the Research Grant of Howon University, Republic of Korea.

\section{Compliance with ethical guidelines}

\section{Competing interests}

The authors declare that they have no competing interests.

Received: 2 February 2015 Accepted: 10 July 2015

Published online: 01 September 2015

\section{References}

Cabrera, R. (1996). Classic tailoring techniques: a construction guide for men's wear. New York: Fairchild Publications.

Cho, R. H. (2008). Establishments of the suitable basic slim fit jacket pattern for man age of 18-24. Unpublished master's thesis, Sungkyunkwan University, Seoul.

Hong, E. H., \& Suh, M. A. (2012). A comparative study on men's bodice slopers-Using a 3D virtual garment system. The Research Journal of the Costume Culture, 20(3), 403-415.

Kang, S. H., \& Suh, M. A. (2007). 의복의 입체구성 [Clothing three-dimensional construction]. Paju: Kyomunsa.

Kim, Y. (2008). An establishments of crotch ease of men's slacks for lower body mobility. The Journal of the Korean Society of Clothing and Textiles, 32(4), 553-561.

Kim, M. O. (2014). A survey on jacket lining manufacture of menswear brands. The Research Journal of the Costume Culture, 22(2), 300-312.

Kim, M. O., \& Kim, I. (2014). Patternmaking for menswear: classic to contemporary. New York: Fairchild Publications.

Kim, M. O., \& Suh, M. A. (2007). A study in the pattern making of the lining fabrics for jackets made of stretchable fabric. The Research Journal of the Costume Culture, 15(6), 1038-1052.

Kim, M. O., Uh, M. K., \& Park, M. J. (2006). A study on the mechanical and hand properties of the lining fabrics. The Journal of The Society of Fashion and Textile Industry, 8(3), 357-362.

Knowles, L. A. (2006). The practical guide to patternmaking for fashion designers. New Yoke: Fairchild Publications.

Kwak, Y. S., Kim, J. Y., \& Baek, Y. H. (2008). 남성복 테일러링 [Men's wear tailoring]. Seoul: Kyoungchunsa.

Lee, M. S., \& Suh, M. A. (2008). A study on the lining pattern making method of pants made of stretchable fabrics. The Research Journal of the Costume Culture, 16(1), 48-57.

Nam, Y. J., \& Lee, H. S. (2005). 남성복연구 [Men's wear research]. Seoul: Kyoungchunsa.

Suh, D. A., \& Chun, J. S. (2004). Men's bodice pattern making method using 3-D body scan data. The Research Journal of Costume Culture, 12(2), 290-299.

Yang, C. E., \& Seong, O. J. (2011). Development of pattern in casual slim-fit jacket for middle-aged men. Journal of Design forum, 32, 382-391. 